\title{
Comparative Performance of CHA2DS2VASc and AnTicoagulation and Risk Factors in Atrial Fibrillation Risk Scores for Predicting Mortality in Patients with COVID-19
}

\author{
Dilay Karabulut, Ersan Oflar ${ }^{1}$ \\ Department of Cardiology, Bakırkoy Dr. Sadi Konuk Training and Research Hospital, ${ }^{1}$ Department of Cardiology, Bakırkoy Dr. Sadi Konuk Educational and Research \\ Hospital, Istanbul, Turkey \\ ORCID: \\ Dilay Karabulut: https://orcid.org/0000-0003-1896-0096 \\ Ersan Oflar: https://orcid.org/0000-0002-0757-2496
}

\section{Abstract}

Background: The AnTicoagulation and Risk factors in Atrial fibrillation (ATRIA) and CHA DS $_{2}$ VASc risk scores used to detect the thromboembolic and hemorrhagic risk in atrial fibrillation (AF) patients has been shown recently to predict poor clinical outcomes varies clinical settings, regardless of having AF. We aimed to examine the potential utility of admission CHA $2 S_{2}$ VASc and ATRIA scores for predicting in-hospital mortality in patients with coronavirus disease 2019 (COVID-19). Methods: In this retrospective study hospitalized 134 COVID-19 patients who diagnosed with a positive polymerase chain reaction test, were included. Patients were divided into two groups who were died and survivors, both the groups were compared according to clinical, laboratory, and demographic features, including the CHA $2 S_{2} V_{2}$ Sc $_{2}$ and ATRIA risk score. Predictors of mortality were determined by logistic regression analysis. Results: ATRIA and CHA DS 2 VASc risk scores were predicting mortality in COVID-19 patients. Logistic regression analysis showed that ATRIA risk score, AF and chronic obstructive pulmonary disease were an independent predictor of mortality. For an ATRIA score cut off value of 3, the sensitivity was $77.78 \%$, specificity $57.94 \%$, positive predictive value 31.80 , and negative predictive value 91.20 . For a $\mathrm{CHA}_{2} \mathrm{DS}_{2}$ VASc score cut-off value of 4 , the sensitivity was $44.44 \%$, specificity $83.18 \%$, positive predictive value 40 , and negative predictive value 85.60 . Conclusion: CHA DS 2 VASc and ATRIA scores can be used as a novel, simple tool for predicting mortality in COVID-19 patients.

Keywords: Atrial, coronavirus, embolism, fibrillation, mortality

\section{INTRODUCTION}

The outbreak of the coronavirus disease 2019 (COVID-19) caused by severe acute respiratory syndrome coronavirus 2 (SARS-CoV-2) has rapidly spread throughout the world..$^{[1]}$

When infected with SARS-CoV-2, patients with preexisting hypertension (HT), diabetes mellitus (DM), coronary artery disease (CAD), cerebrovascular disease (CVD), chronic obstructive pulmonary disease (COPD), and kidney dysfunction have worse clinical outcomes than those without them. $\cdot^{[2]}$

\section{Received: 02-12-2020 Revised: 02-02-2021 Accepted: 03-03-2021}

Published Online: 05-07-2021

\begin{tabular}{|l|l|}
\hline \multicolumn{3}{|c|}{ Access this article online } \\
\hline Quick Response Code: & Website: \\
\hline
\end{tabular}

COVID-19 may predispose both venous and arterial thromboembolic diseases due to excessive inflammation, hypoxia, immobilization, and diffuse intravascular coagulation. ${ }^{[3-6]}$ Precise knowledge of the incidence of thrombotic complications in COVID-19 patients is essential for decision-making about the intensity of thromboprophylaxis, especially in patients admitted to the intensive care unit who are at the highest thrombotic risk. ${ }^{[7]}$

Address for correspondence: Dr. Dilay Karabulut, Bakırkoy Dr. Sadi Konuk Training and Research Hospital, Zuhuratbaba Avenue Tevfik Sağlam Street, Bakırköy 34147, İstanbul, Turkey. E-mail: dilay_karakozak@hotmail.com

This is an open access journal, and articles are distributed under the terms of the Creative Commons Attribution-NonCommercial-ShareAlike 4.0 License, which allows others to remix, tweak, and build upon the work non-commercially, as long as appropriate credit is given and the new creations are licensed under the identical terms.

For reprints contact: WKHLRPMedknow_reprints@wolterskluwer.com

How to cite this article: Karabulut D, Oflar E. Comparative performance of CHA2DS2VASc and anticoagulation and risk factors in atrial fibrillation risk scores for predicting mortality in patients with COVID-19. Int J Cardiovasc Acad 2021;7:33-8. 
In the practice of cardiology, simple clinical risk scores have been used to define the risks in different clinical settings, such as atrial fibrillation (AF). The $\mathrm{CHA}_{2} \mathrm{DS}_{2}$ VASc (Congestive heart failure $[\mathrm{CHF}], \mathrm{HT}$, age, diabetes, previous stroke/ transient ischemic attack [TIA], vascular disease, and sex category [female gender]) risk score has been recommended by the guidelines for stroke risk stratification and further guides the optimization of anticoagulation therapy in patients with nonvalvular AF. ${ }^{[8,9]}$ In recent years, the use of the $\mathrm{CHA}_{2} \mathrm{DS}_{2}$ VASc score in predicting ischemic stroke, thromboembolism, and death has extended beyond the original disease state for which it was proposed. ${ }^{[10,11]}$ Current studies have shown that the more recently developed AnTicoagulation and Risk factors In Atrial fibrillation (ATRIA) RS determine the predisposition to thromboembolic and hemorrhagic events in AF, which demonstrates better accuracy than the $\mathrm{CHA}_{2} \mathrm{DS}_{2}$ VASc score in predicting ischemic stroke. ${ }^{[12-14]}$ This score is a newly proposed stroke risk-stratification tool derived from the ATRIA cohort and validated in the external ATRIA-Cardiovascular (CV) Research Network cohort. ${ }^{[15]}$

With the spread of SARS-CoV-2 and a rise in the number of cases, an increasing number of SARS-CoV-2-infected patients exhibit comorbidities such as HT, diabetes, and cardiac and CVDs. ${ }^{[16]}$ Depending on the inflammatory reaction, the entire microvascular system may be damaged, leading to abnormal activation of the coagulation system, which pathologically represents vasculitis and microthrombosis. ${ }^{[17,18]}$

Although the mortality rate in COVID-19 infection is not high, SARS-CoV-2 is highly contagious, and the rapidity of the spread of the infection has resulted in a pandemic. Therefore, risk-scoring systems are important for clinicians in managing and treating and predicting mortality in infected patients.

In this study, we aimed to examine the potential utility of admission $\mathrm{CHA}_{2} \mathrm{DS}_{2}$ VASc and ATRIA scores in predicting the in-hospital mortality in patients with COVID-19.

\section{Methods}

In this retrospective, single-center study hospitalized, COVID-19 patients aged 18 years and above who underwent a positive polymerase chain reaction (PCR) test at diagnosis between March 28, 2020, and April 25, 2020, were included. The patients' demographic characteristics, relevant clinical data, comorbidities, and biochemical markers were obtained from the hospital's electronic database. HT was defined as receiving antihypertensive treatment or systolic pressure $>140 \mathrm{~mm} \mathrm{Hg}$ and/or diastolic pressure $>90 \mathrm{~mm} \mathrm{Hg}$ on at least 2 separate measurements during hospitalization. ${ }^{[19]}$ DM was defined as taking oral antidiabetic agents or insulin or follow-up fasting blood glucose levels $\geq 126 \mathrm{mg} / \mathrm{dL}$ in accordance with the criteria of the American Diabetes Association. ${ }^{[20]}$ Hyperlipidemia was defined as taking lipid-lowering medications on presentation. ${ }^{[21]}$ Chronic kidney disease (CKD) was considered in the presence of an estimated glomerular filtration rate (GFR) 3 months, with or without kidney damage. ${ }^{[22]} \mathrm{CHF}$ and CAD were defined based on a previous data. The $\mathrm{CHA}_{2} \mathrm{DS}_{2}$ VASc and ATRIA scores of each patient were calculated.

The $\mathrm{CHA}_{2} \mathrm{DS}_{2}$ VASc score was calculated by allotting one point each for CHF, HT, DM, age between 65 and 74 years, female gender, and vascular disease two points each for age $\geq 75$ years and a history of stroke or TIA. The risk factors assessed in the ATRIA risk score are shown in Table 1.

COVID-19 patients aged 18 years and above who underwent a positive PCR test at diagnosis were enrolled into the study. Patients who have malignancy, pregnancy, and insufficient data were excluded from the study.

The local ethics committee approved the study protocol (2020/175) and the study was carried out according to the principles of the Declaration of Helsinki (2013).

\section{Ethical statement}

Bakırkoy Dr. Sadi Konuk Educational and Research Hospital committee approved the study protocol (2020/175) and the study was carried out according to the principles of the Declaration of Helsinki (2013).

\section{Statistical analysis}

Statistical analysis of the variables was performed using SPSS version 20.0 (IBM corp., Armonk, NY, USA). Descriptive statistical methods (mean, standard deviation [SD], median, frequency, percentage, and minimum and maximum) were used for evaluating the study data. The distribution of variables was tested using the Shapiro-Wilk test and by graphical examination. Student's $t$-test was used for the comparison between two groups with the normal distribution of quantitative variables, and the Mann-Whitney $U$-test was used for the comparison between two groups with nonnormally distributed quantitative variables. Quantitative variables are expressed as mean $\pm \mathrm{SD}$, median \pm interquartile range, or median (minimum/maximum), while categorical variables are expressed as $n(\%)$. Pearson's Chi-square test and Fisher's exact test were used to comparing qualitative data. Diagnostic

\begin{tabular}{|c|c|c|}
\hline Risk factor & $\begin{array}{l}\text { Points without } \\
\text { prior stroke }\end{array}$ & $\begin{array}{l}\text { Points with } \\
\text { prior stroke }\end{array}$ \\
\hline \multicolumn{3}{|l|}{ Age (years) } \\
\hline$>85$ & 6 & 9 \\
\hline $75-84$ & 5 & 7 \\
\hline $65-74$ & 3 & 7 \\
\hline$<65$ & 0 & 0 \\
\hline Female & 1 & 1 \\
\hline $\mathrm{DM}$ & 1 & 1 \\
\hline $\mathrm{CHF}$ & 1 & 1 \\
\hline HT & 1 & 1 \\
\hline Proteinuria & 1 & 1 \\
\hline eGFR $<45$ or ESRD & 1 & 1 \\
\hline
\end{tabular}

eGFR: Estimated glomerular filtration rate, ESRD: End-stage renal disease, CHF: Congestive heart failure, DM: Diabetes mellitus, HT: Hypertension 
screening tests (sensitivity, specificity, polycystic kidney disease, and nonspesific kidney disease), a receiver operating characteristic (ROC) curve analysis, and the exact binomial test were used to determine the predictive values of the parameters. The confidence level (CI) for the variables was set at $95 \%$, with $P<0.05$ deemed statistically significant. We used logistic regression analysis for evaluating the effects of variables such as age, HT, DM, CAD, CHF, AF, COPD, and chronic renal failure, $\mathrm{CHA}_{2} \mathrm{DS}_{2}$ VASc and ATRIA scores, GFR, c-reactive protein (CRP), procalcitonin, D-dimer, troponin with $P<0.05$ on mortality.

\section{RESULTS}

Data of 261 patients were evaluated. Patients whose electronic data could not be obtained and pregnant women were excluded from the study. Overall, 134 patients were included in the final analysis. The mean age was $60.78 \pm 13.12$ (19-91) years, and $67 \%(n=90)$ were male. Baseline clinical characteristics of patients in relation to mortality are presented in Table 2 . The incidence of $\mathrm{HT}, \mathrm{CAD}, \mathrm{CHF}, \mathrm{AF}, \mathrm{COPD}$ were statistically higher in deceased patients $(P=0.005, P=0.007, P=0.003$, $P=0.026, P=0.033)$. No statistically significant differences were found in terms of age, gender, smoking status, diabetes, hyperlipidemia, CKD, and CVD $(P>0.05)$ [Table 2]. The mortality causes of the deceased patients were acute respiratory failure in $20(74 \%)$ patients, pulmonary embolism in $3(11 \%)$ patients, myocardial infarction in $4(15 \%)$ patients.

The serum creatine kinase-myocardial band, aspartate aminotransferase, alanine aminotransferase, calcium $(\mathrm{Ca})$, phosphorus $(\mathrm{P})$, magnesium $(\mathrm{Mg})$, sodium $(\mathrm{Na})$, potassium $(\mathrm{K})$, ferritin, platelet, and monocyte measurements did not show significant differences in relation to mortality $(P>0.05)$.

\begin{tabular}{|c|c|c|c|c|}
\hline & Total (\%) & $\begin{array}{c}\text { Survivors } \\
(\%)\end{array}$ & $\begin{array}{c}\text { Nonsurvivors } \\
(\%)\end{array}$ & $P$ \\
\hline Age, mean \pm SD & $60.78 \pm 13.12$ & $59.92 \pm 13.53$ & $64.22 \pm 10.90$ & $0.128^{\mathrm{a}}$ \\
\hline \multicolumn{5}{|l|}{ Gender } \\
\hline Female & $44(32.8)$ & $33(30.8)$ & $11(40.7)$ & $\chi^{2}: 0.958$ \\
\hline Male & $90(67.2)$ & $74(69.2)$ & $16(59.3)$ & $0.328^{\mathrm{b}}$ \\
\hline Smoking & $5(12.5)$ & $4(10.5)$ & $1(50.0)$ & $0.237^{c}$ \\
\hline HT & $72(53.7)$ & $51(47.7)$ & $21(77.8)$ & $0.005^{* *, \mathrm{~b}}$ \\
\hline Diabetes & $38(28.4)$ & $27(25.2)$ & $11(40.7)$ & $0.110^{\mathrm{b}}$ \\
\hline Hyperlipidemia & $12(9.0)$ & $9(8.4)$ & $3(11.1)$ & $0.707^{\mathrm{c}}$ \\
\hline CAD & $25(18.9)$ & $15(14.3)$ & $10(37.0)$ & $0.007^{* *, \mathrm{~b}}$ \\
\hline Heart failure & $12(9.0)$ & $5(4.7)$ & $7(25.9)$ & $0.003 * *, \mathrm{c}$ \\
\hline $\mathrm{AF}$ & $4(3.0)$ & $1(0.9)$ & $3(11.1)$ & $0.026^{*, c}$ \\
\hline COPD & $7(5.3)$ & $3(2.9)$ & $4(14.8)$ & $0.033^{*, \mathrm{c}}$ \\
\hline CKD & $16(12.0)$ & $10(9.4)$ & $6(22.2)$ & $0.094^{c}$ \\
\hline CVD & $3(2.3)$ & $3(2.8)$ & 0 & $1.000^{\mathrm{c}}$ \\
\hline
\end{tabular}

${ }^{a}$ Student $t$-test, ${ }^{b}$ Pearson Chi-square test, ${ }^{\text {c}}$ Fisher's exact test, ${ }^{*} P<0.05$, ${ }^{*} P<0.01$. COPD: Chronic obstructive pulmonary disease, SD: Standard deviation, CKD: Chronic kidney disease, CAD: Coronary artery disease, HT: Hypertension, AF: Atrial fibrillation, CVD: Cerebrovascular disease
However, the troponin, urea, creatinine, triglyceride, lactate dehydrogenase, CRP, procalcitonin, activated partial thromboplastin time, D-dimer, white blood cell, and lymphocyte levels of deceased patients were found to be significantly higher than those of survivors (all $P<0.01$ ). The GFR and $\mathrm{Hg}$ values of deceased patients were significantly lower than those of survivors $(P=0.001, P=0.004$, respectively). The patients' biochemical parameters are summarized in Table 3.

While the mean ATRIA score of the deceased patients was 4.3 , it was found to be 2.79 for the survivors. The ATRIA score of deceased patients was significantly higher than that of survivors. $(P=0.003)$. The mean $\mathrm{CHA}_{2} \mathrm{DS}_{2}$ VASc score was 2.9 for deceased patients and 1.8 for survivors. The $\mathrm{CHA}_{2} \mathrm{DS}_{2} \mathrm{VASc}$ score of the patients who died was significantly higher than that of survivors $(P=0.001)$ [Table 4 ].

The effects of the age, ATRIA score, $\mathrm{CHA}_{2} \mathrm{DS}_{2} \mathrm{VASc}$ score and the presence of HT, DM, CAD, CHF, AF, COPD, and CKD, troponin, GFR, CRP, procalcitonin, D-Dimer on mortality were evaluated using logistic regression analysis; the model was found to be significant, and the explanatory coefficient was good (87.3\%) [Table 5]. While the CHF, COPD, CKD, GFR, CRP, and procalcitonin were found to be independent risk factors that had a significant effect on mortality $(P<0.05)$, the effects of the other variables were not significant $(P>0.05)$. CHF ([odds ratio $(\mathrm{OR})]$ : 50,374; 95\% CI: $6.18-410,78 ; P=0.000$ ), CKD ([OR]: 0,$113 ; 95 \%[\mathrm{CI}]: 0.01-0.935 ; P=0.043$ ), and COPD ([OR]: 31.170 (\%95 CI: 3.454-281.31; $P=0.002)$ were associated with an increased risk of mortality in COVID-19 patients. The effect of one unit increase in GFR, CRP, procalcitonin on mortality increased the OR by 0.963 (95\% CI: 0.940-0.986), 1.007 (95\% CI: $1.001-1.013), 1.111$ (95\% CI: 1.042-1.182) times, respectively [Table 5].

Based on the ROC curve analysis, the cut-off point obtained for the ATRIA score was determined as 3, the sensitivity was $77.78 \%$, specificity $57.94 \%$, positive predictive value 31.80 , and negative predictive value 91.20 , area under the curve (AUC) value was 0.686 (95\% CI: $0.588-0.784$, $P=0.003$ ). The cut-off point obtained for the $\mathrm{CHA}_{2} \mathrm{DS}_{2} \mathrm{VASc}$ score was determined as 2 , the sensitivity was $77.78 \%$, specificity $48.60 \%$, positive predictive value 27.63 , and negative predictive value 89.66 , AUC value was $0.706(95 \%$ CI: $0.603-0.809, P=0.039$ ) [Figure 1].

\section{Discussion}

The current study, both the ATRIA and $\mathrm{CHA}_{2} \mathrm{DS}_{2}$ VASc RS were statistically higher in deceased patients with COVID- 19. Our study also demonstrated that the ATRIA RS was similar to the $\mathrm{CHA}_{2} \mathrm{DS}_{2} \mathrm{VASc}$ RS in determining in-hospital mortality. Both scores demonstrated a high negative predictive value for mortality in COVID-19 patients.

The $\mathrm{CHA}_{2} \mathrm{DS}_{2}$ VASc and ATRIA risk scores were mainly developed and validated to estimate the risk of thromboembolism 


\begin{tabular}{|c|c|c|c|c|}
\hline & \multicolumn{3}{|c|}{ Mean \pm SD } & \multirow[t]{2}{*}{$P$} \\
\hline & Total & Survivor $(n=107)$ & Nonsurvivor $(n=27)$ & \\
\hline CKMB (U/L) & $8.64 \pm 13.02$ & $6.95 \pm 10.71$ & $11.69 \pm 16.25$ & $0.422^{\mathrm{d}}$ \\
\hline Troponin (ng/ml) & $1320.05 \pm 7958.93$ & $666.83 \pm 3018.38$ & $3836.19 \pm 16503.02$ & $0.001 * *, \mathrm{~d}$ \\
\hline Urea (mg/dl) & $51.77 \pm 34.2$ & $45.49 \pm 28.84$ & $76.63 \pm 42.27$ & $0.001 * *, \mathrm{~d}$ \\
\hline Creatinine (mg/dl) & $1.31 \pm 1.46$ & $1.21 \pm 1.4$ & $1.7 \pm 1.66$ & $0.008^{* *, \mathrm{~d}}$ \\
\hline $\operatorname{GFR}\left(\mathrm{ml} / \mathrm{min} / 1.73 \mathrm{~m}^{2}\right)$ & $80.24 \pm 31.79$ & $85.02 \pm 29.09$ & $61.3 \pm 35.42$ & $0.001^{* *, \mathrm{a}}$ \\
\hline Triglycerides (mg/dl) & $149.39 \pm 105.41$ & $138.37 \pm 85.15$ & $199.5 \pm 163.18$ & $0.004 * *, \mathrm{~d}$ \\
\hline AST (UL) & $160.63 \pm 733.47$ & $107.83 \pm 343.11$ & $369.85 \pm 1488.31$ & $0.128^{\mathrm{d}}$ \\
\hline ALT (IUL) & $80.52 \pm 372.02$ & $46.75 \pm 83.41$ & $214.33 \pm 810.14$ & $0.126^{\mathrm{d}}$ \\
\hline LDH (UL) & $373.95 \pm 184.64$ & $341.27 \pm 143.6$ & $503.44 \pm 261.76$ & $0.002 * *, \mathrm{~d}$ \\
\hline CRP (mg/L) & $100.37 \pm 94.72$ & $86.9 \pm 86.69$ & $153.75 \pm 107.46$ & $0.001^{* *, \mathrm{~d}}$ \\
\hline Ferritin & $810.03 \pm 1763.4$ & $737.97 \pm 1917.6$ & $810.03 \pm 932.31$ & $0.059^{\mathrm{d}}$ \\
\hline Procalcitonin (ng/ml) & $3.15 \pm 10.33$ & $1.15 \pm 4.59$ & $11 \pm 19.4$ & $0.001^{* *, \mathrm{~d}}$ \\
\hline aPTT (sn) & $40.43 \pm 17.36$ & $38.88 \pm 17.28$ & $46.66 \pm 16.58$ & $0.013^{*, \mathrm{~d}}$ \\
\hline D-dimer $(\mu \mathrm{gFEU} / \mathrm{ml})$ & $1.56 \pm 3.66$ & $1.19 \pm 3.53$ & $2.97 \pm 3.89$ & $0.001^{* *, \mathrm{~d}}$ \\
\hline WBC $(10 \mathrm{e} 3 / \mathrm{uL})$ & $8.22 \pm 4.8$ & $7.38 \pm 4.37$ & $11.54 \pm 5.03$ & $0.001^{* *, \mathrm{~d}}$ \\
\hline Hemoglobin (g/dl) & $11.66 \pm 2.14$ & $11.93 \pm 2.06$ & $10.6 \pm 2.18$ & $0.004 * *, \mathrm{a}$ \\
\hline PLT (10e3/uL) & $226.81 \pm 101.57$ & $232.58 \pm 105.60$ & $204.15 \pm 81.70$ & $0.429^{\mathrm{d}}$ \\
\hline Lymphocyte & $1.81 \pm 3.76$ & $1.61 \pm 2.06$ & $2.62 \pm 7.33$ & $0.005^{* *, \mathrm{~d}}$ \\
\hline
\end{tabular}

\begin{tabular}{|c|c|c|c|c|}
\hline & Total & Survivor & Nonsurvivor & $P$ \\
\hline \multicolumn{5}{|l|}{ ATRIA } \\
\hline Minimum-maximum (median) & $0-8(2)$ & $0-8(2)$ & $1-8(4)$ & $0.003 * *$ \\
\hline Mean \pm SD & $3.09 \pm 2.57$ & $2.79 \pm 2.57$ & $4.30 \pm 2.25$ & \\
\hline \multicolumn{5}{|l|}{$\mathrm{CHA}_{2} \mathrm{DS}_{2} \mathrm{VASc}$} \\
\hline Minimum-maximum (median) & $0-5(2)$ & $0-5(2)$ & $1-5(3)$ & $0.001 * *$ \\
\hline Mean \pm SD & $2.01 \pm 1.49$ & $1.79 \pm 1.44$ & $2.89 \pm 1.40$ & \\
\hline
\end{tabular}

in patients with nonvalvular AF. ${ }^{[23]}$ Singer et al. reported that the ATRIA RS showed a better performance than the $\mathrm{CHA}_{2} \mathrm{DS}_{2}$ VASc score in predicting ischemic stroke, especially in the low-risk group ${ }^{[24]}$ and similar results have also been reported in different patient cohorts. ${ }^{[25,26]}$ However, in some studies, the opposite results have been shown. ${ }^{[27-29]}$

In the COVID-19 pandemic, the pulmonary complications have been the primary focus of healthcare providers, but they need to be aware of the $\mathrm{CV}$ and thromboembolic complications, which can be substantial contributors to the mortality associated with this disease. ${ }^{[30,31]}$ SARS-CoV-2 not only causes viral pneumonia but also has a major impact on the CV system. Patients with $\mathrm{CV}$ risk factors including the male sex, an advanced age, the presence of DM, HT, or obesity, as well as patients with established CV and CVDs have been identified as particularly vulnerable populations at an increased risk of morbidity and mortality from COVID-19. Moreover, a considerable proportion of patients may develop a cardiac injury in the context of COVID-19, which portends an increased risk of in-hospital mortality. ${ }^{[32]}$
Therefore, in this study, our objective was to estimate the risk of mortality in COVID-19 patients using these risk-scoring tools. Although both these scores were developed for predicting thromboembolic events in patients with AF, based on different studies and the current guidelines, their constituent components such as old age, DM, renal dysfunction, heart failure, and prior vascular disease are common predictors of poor prognosis in patients having COVID-19. ${ }^{[33]}$

In this study, CHF, CKD, COPD, GFR, CRP, and procalcitonin were found to be independent risk factors for mortality, and the effects of the other variables on mortality were not significant. The other principal finding in this study was that both $\mathrm{CHA}_{2} \mathrm{DS}_{2}$ VASc and ATRIA RS of the patients who died were significantly higher than those of survivors. We demonstrated that a $\mathrm{CHA}_{2} \mathrm{DS}_{2} \mathrm{VASc}$ score of 2 can be used as a cut off value with a sensitivity of $77.78 \%$ and a specificity of $48.60 \%$, and an ATRIA score of 3 can be used as a cut off value with a sensitivity of $77.78 \%$ and a specificity of $57.94 \%$. 


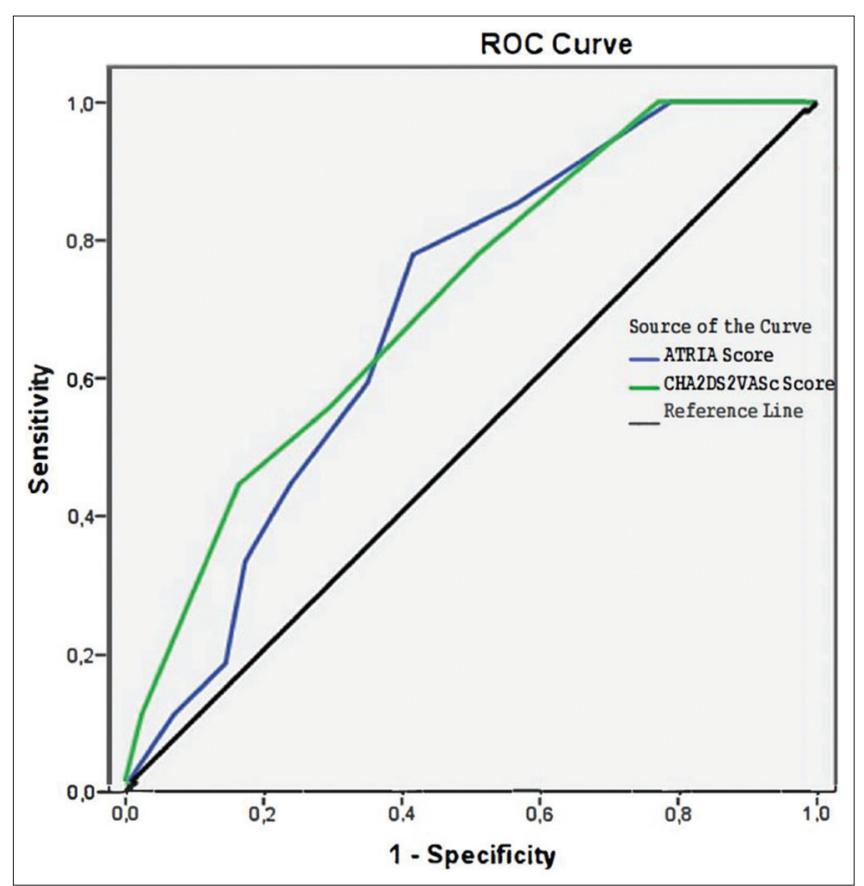

Figure 1: Receiver operating characteristic curve analysis, for the AnTicoagulation and Risk factors in Atrial fibrillation and $\mathrm{CHA}_{2} \mathrm{DS}_{2} \mathrm{VASc}$ score. For an AnTicoagulation and Risk factors in Atrial fibrillation score cut-off value of 3 , the sensitivity was $77.78 \%$, specificity $57.94 \%$, positive predictive value 31.80 , and negative predictive value 91.20 . For a $\mathrm{CHA}_{2} \mathrm{DS}_{2}$ VASc score cut-off value of 4 , the sensitivity was $44.44 \%$, specificity $83.18 \%$, positive predictive value 40 , and negative predictive value 85.60

\begin{tabular}{|c|c|c|c|c|}
\hline & $P$ & $\begin{array}{c}95 \% \mathrm{Cl} \text {, } \\
\text { odds }\end{array}$ & $\begin{array}{l}\text { Odds } \\
\text { lower }\end{array}$ & $\begin{array}{l}\text { Odds } \\
\text { upper }\end{array}$ \\
\hline Age & 0.148 & 0.943 & 0.870 & 1.021 \\
\hline HT & 0.746 & 1.384 & 0.193 & 9.948 \\
\hline Diabetes & 0.126 & 3.535 & 0.703 & 17.790 \\
\hline $\mathrm{CAD}$ & 0.071 & 6.828 & 0.845 & 55.148 \\
\hline $\mathrm{CHF}$ & $0.000 * *$ & 50.374 & 6.177 & 410.787 \\
\hline $\mathrm{AF}$ & 0.114 & 18.663 & 0.494 & 704.868 \\
\hline COPD & $0.002 * *$ & 31.170 & 3.454 & 281.319 \\
\hline CKD & $0.043 *$ & 0.113 & 0.014 & 0.935 \\
\hline Troponin & 0.483 & 1.000 & 1.000 & 1.000 \\
\hline GFR & $0.002 * *$ & 0.963 & 0.940 & 0.986 \\
\hline CRP & $0.018^{*}$ & 1.007 & 1.001 & 1.013 \\
\hline Procalcitonin & $0.001 * *$ & 1.111 & 1.044 & 1.182 \\
\hline D-dimer & 0.861 & 0.989 & 0.869 & 1.124 \\
\hline ATRIA score $(\geq 3)$ & 0.096 & 7.206 & 0.705 & 73.636 \\
\hline $\mathrm{CHA}_{2} \mathrm{DS}_{2}$ VASc $(\geq 2)$ & 0.415 & 0.353 & 0.029 & 4.324 \\
\hline
\end{tabular}

$* P<0.05, * * P<0.01$. ATRIA: Anticoagulation and risk factors in atrial fibrillation, CI: Confidence interval, COPD: Chronic obstructive pulmonary disease, GFR: Glomerular filtration rate, CRP: C-reactive protein, CKD: Chronic kidney disease, CAD: Coronary artery disease, CHF: Congestive heart failure, HT: Hypertension, AF: Atrial fibrillation

Previous studies have investigated the clinical application and the importance of these scores in various clinical settings. One study demonstrated that the $\mathrm{CHA}_{2} \mathrm{DS}_{2}$ VASc risk score could be an independent predictor of no-reflow in patients with ST-elevation myocardial infarction (STEMI). ${ }^{[34]}$ Other studies that evaluated the potential value of the $\mathrm{CHA}_{2} \mathrm{DS}_{2}$ VASc score in predicting the risk of adverse $\mathrm{CV}$ outcomes among patients with acute coronary syndrome showed that an elevated $\mathrm{CHA}_{2} \mathrm{DS}_{2}$ VASc score was independently associated with increased in-hospital and long-term mortality. ${ }^{[35-37]} \mathrm{A}$ recent study on the association between $\mathrm{CHA}_{2} \mathrm{DS}_{2} \mathrm{VASc}$ scores and acute stent thrombosis in patients with stable CAD and acute coronary syndrome, a score of 3 or more had an independent predictive value for acute stent thrombosis. ${ }^{[38]}$

Furthermore, Aksoy and Bagci demonstrated that the ATRIA and $\mathrm{CHA}_{2} \mathrm{DS}_{2}$ VASc scoring systems were useful in detecting contrast-induced nephropathy following STEMI. ${ }^{[39]}$

In terms of the applicability of the $\mathrm{CHA}_{2} \mathrm{DS}_{2}$ VASc and ATRIA scores in routine clinical practice for patients with COVID-19, data presented here may help health professionals to identify high-risk patients based on their $\mathrm{CHA}_{2} \mathrm{DS}_{2}$ VASc and ATRIA scores. It is important for clinicians to be aware of these comorbidities when treating patients with COVID-19 as such patients are more likely to require critical care.

\section{Limitations}

This study has some limitations. The sample size was relatively small, we have insufficient data such as electrocardiographic parameters, blood pressure, body mass index, oxygen saturate, drugs on admission and the study was conducted using data from a single center. Although COVID-19 is associated with thromboembolic complications, and both scores have mainly been developed to assess these events, we did not specifically investigate any thrombotic events and reported all-cause mortality instead. According to the suggestions of the Turkish Society of Cardiology's Consensus Report on the COVID-19 Pandemic and CVDs, transthoracic echocardiography (TTE) was not performed routinely in all COVID-19 patients. Therefore, echocardiographic data could not be obtained for all patients. TTE was only performed in 26 patients.

\section{Conclusion}

We believe that the CHA, $\mathrm{DS}_{2}$ VASc and ATRIA scores, which can be easily implemented in day-to-day clinical practice, may serve as simple yet effective tools for predicting high risk patients with COVID-19.

\section{Financial support and sponsorship \\ Nil.}

\section{Conflicts of interest}

There are no conflicts of interest.

\section{REFEREnCES}

1. Bogoch II, Watts A, Thomas-Bachli A, Huber C, Kraemer MU, Khan K. Potential for global spread of a novel coronavirus from China. J Travel Med 2020;27:taaa011.

2. Ji HL, Zhao R, Matalon S, Matthay MA. Elevated plasmin (ogen) as a common risk factor for COVID-19 susceptibility. Physiol Rev 
2020;100:1065-75.

3. Chen T, Wu D, Chen H, Yan W, Yang D, Chen G, et al. Clinical characteristics of 113 deceased patients with coronavirus disease 2019: Retrospective study. BMJ 2020;368:m1091.

4. Guan WJ, Ni ZY, Hu Y. Clinical characteristics of coronavirus disease 2019 in China. N Engl J Med 2020;382:1708-20.

5. Wang D, Hu B, Hu C, Zhu F, Liu X, Zhang J, et al. Clinical characteristics of 138 hospitalized patients with 2019 novel coronavirus-infected pneumonia in Wuhan, China. JAMA 2020;323:1061-9.

6. Zhou F, Yu T, Du R, Fan G, Liu Y, Liu Z, et al. Clinical course and risk factors for mortality of adult inpatients with COVID-19 in Wuhan, China: A retrospective cohort study. Lancet 2020;395:1054-62.

7. Klok FA, Kruip MJ, van der Meer NJ, Arbous MS, Gommers DA, Kant KM, et al. Incidence of thrombotic complications in critically ill ICU patients with COVID-19. Thromb Res 2020;191:145-7.

8. Kirchhof P, Benussi S, Kotecha D, Ahlsson A, Atar D, Casadei B, et al. 2016 ESC Guidelines for the management of atrial fibrillation developed in collaboration with EACTS. Eur Heart J 2016;37:2893-962.

9. Lip GY, Nieuwlaat R, Pisters R, Lane DA, Crijns HJ. Refining clinical risk stratification for predicting stroke and thromboembolism in atrial fibrillation using a novel risk factor-based approach: The Euro Heart Survey on atrial fibrillation. Chest 2010;137:263-72.

10. Lip GY, Lin HJ, Chien KL, Hsu HC, Su TC, Chen MF, et al. Comparative assessment of published atrial fibrillation stroke risk stratification schemes for predicting stroke, in a non-atrial fibrillation population: The Chin-Shan Community Cohort Study. Int J Cardiol 2013;168:414-9.

11. Mitchell LB, Southern DA, Galbraith D, Ghali WA, Knudtson M, Wilton SB, et al. Prediction of stroke or TIA in patients without atrial fibrillation using CHADS2 and CHA2DS2-VASc scores. Heart 2014;100:1524-30.

12. Singer DE, Chang Y, Borowsky LH, Fang MC, Pomernacki NK, Udaltsova $\mathrm{N}$, et al. A new risk scheme to predict ischemic stroke and other thromboembolism in atrial fibrillation: The ATRIA study stroke risk score. J Am Heart Assoc 2013;2:e000250.

13. van den Ham HA, Klungel OH, Singer DE, Leufkens HG, van Staa TP. Comparative performance of ATRIA, CHADS2, and CHA2DS2-VASc risk scores predicting stroke in patients with atrial fibrillation: Results from a national primary care database. J Am Coll Cardiol 2015;66:1851-9.

14. Aspberg S, Chang Y, Atterman A, Bottai M, Go AS, Singer DE. Comparison of the ATRIA, CHADS2, and CHA2DS2-VASc stroke risk scores in predicting ischaemic stroke in a large Swedish cohort of patients with atrial fibrillation. Eur Heart J 2016;37:3203-10.

15. Singer DE, Chang Y, Borowsky LH, Fang MC, Pomernacki NK, Udaltsova $\mathrm{N}$, et al. A new risk scheme to predict ischemic stroke and other thromboembolism in atrial fibrillation: The ATRIA study stroke risk score. J Am Heart Assoc 2013;2:e000250.

16. Sanyaolu A, Okorie C, Marinkovic A, Patidar R, Younis K, Desai P, Hosein Z, Padda I, Mangat J, Altaf M. Comorbidity and its Impact on Patients with COVID-19. SN Compr Clin Med 2020:1-8.

17. Tian S, Hu W, Niu L, Liu H, Xu H, Xiao SY. Pulmonary pathology of early-phase 2019 Novel Coronavirus (COVID-19) pneumonia in two patients with lung cancer. J Thorac Oncol 2020;15:700-4.

18. Ding YQ, Bian XW. Analysis of coronavirus disease-19 (COVID-19). Chin J Pathol 2020;49:E003.

19. Mancia G, Fagard R, Narkiewicz K, Redon J, Zanchetti A, Böhm M, et al. $2013 \mathrm{ESH} / \mathrm{ESC}$ guidelines for the management of arterial hypertension: The Task Force for the Management of Arterial Hypertension of the European Society of Hypertension (ESH) and of the European Society of Cardiology (ESC). Eur Heart J 2013;34:2159-219.

20. Mancia G, De Backer G, Dominiczak A, Cifkova R, Fagard R, Germano G, et al. 2007 Guidelines for the management of arterial hypertension: The Task Force for the Management of Arterial Hypertension of the European Society of Hypertension (ESH) and of the European Society of Cardiology (ESC). J Hypertens 2007;25:1105-87.

21. Koskinas KC, Siontis GC, Piccolo R, Mavridis D, Räber L, Mach F, et al. Effect of statins and non-statin LDL-lowering medications on cardiovascular outcomes in secondary prevention: A meta-analysis of randomized trials. Eur Heart J 2018;39:1172-80.

22. Mehran R, Nikolsky E. Contrast-induced nephropathy: Definition, epidemiology, and patients at risk. Kidney Int Suppl 2006;100:S11-5.

23. Aspberg S, Chang Y, Atterman A, Bottai M, Go AS, Singer DE. Comparison of the ATRIA, CHADS2, and CHA2DS2-VASc stroke risk scores in predicting ischaemic stroke in a large Swedish cohort of patients with atrial fibrillation. Eur Heart J 2016;37:3203-10.

24. Singer DE, Chang Y, Borowsky LH, Fang MC, Pomernacki NK, Udaltsova $\mathrm{N}$, et al. A new risk scheme to predict ischemic stroke and other thromboembolism in atrial fibrillation: The ATRIA study stroke risk score. J Am Heart Assoc 2013;2:e00250.

25. van den Ham HA, Klungel OH, Singer DE, Leufkens HG, van Staa TP. Comparative performance of ATRIA, CHADS2, and CHA2DS2-VASc risk scores predicting stroke in patients with atrial fibrillation: Results from a national primary care database. J Am Coll Cardiol 2015;66:1851-9.

26. Aspberg S, Chang Y, Atterman A, Bottai M, Go AS, Singer DE. Comparison of the ATRIA, CHADS2, and CHA2DS2-VASc stroke risk scores in predicting ischaemic stroke in a large Swedish cohort of patients with atrial fibrillation. Eur Heart J 2016;37:3203-10.

27. Abumuaileq RR, Abu-Assi E, López-López A, Raposeiras-Roubin S, Rodríguez-Mañero M, Martínez-Sande L, et al. Comparison between CHA2DS2-VASc and the new R2CHADS2 and ATRIA scores at predicting thromboembolic event in non-anticoagulated and anticoagulated patients with non-valvular atrial fibrillation. BMC Cardiovasc Disord 2015;15:156.

28. Lip GY, Nielsen PB, Skjøth F, Lane DA, Rasmussen LH, Larsen TB. The value of the European society of cardiology guidelines for refining stroke risk stratification in patients with atrial fibrillation categorized as low risk using the anticoagulation and risk factors in atrial fibrillation stroke score: A nationwide cohort study. Chest 2014;146:1337-46.

29. Chao TF, Liu CJ, Wang KL, Lin YJ, Chang SL, Lo LW, et al. Using the CHA2DS2-VASc score for refining stroke risk stratification in 'low-risk' Asian patients with atrial fibrillation. J Am Coll Cardiol 2014;64:1658-65

30. Driggin E, Madhavan MV, Bikdeli B, Chuich T, Laracy J, Biondi-Zoccai G, et al. Cardiovascular considerations for patients, health care workers, and health systems during the COVID-19 pandemic. J Am Coll Cardiol 2020;75:2352-71.

31. Wu Z, McGoogan JM. Characteristics of and important lessons from the coronavirus disease 2019 (COVID-19) outbreak in China: Summary of a report of 72314 cases from the Chinese center for disease control and prevention. JAMA 2020;323:1239-42.

32. ESC Guidance for the Diagnosis and Management of CV Disease during the COVID-19 Pandemic. https://www.escardio.org/static-file/Escardio/ Education-General/Topic\%20pages/Covid-19/ESC\%20Guidance\%20 Document/ESC-Guidance-COVID-19-Pandemic.pdf. [Last accessed on 2021 May 27]

33. Lee JY, Kim HA, Huh K, Hyun M, Rhee JY, Jang S, et al. Risk factors for mortality and respiratory support in elderly patients hospitalized with COVID-19 in Korea. J Korean Med Sci 2020;35:e223.

34. Ipek G, Onuk T, Karatas MB, Gungor B, Osken A, Keskin M, et al. CHA2DS2-VASc score is a predictor of no-reflow in patients with ST-segment elevation myocardial infarction who underwent primary percutaneous intervention. Angiology 2016;67:840-5.

35. Huang SS, Chen YH, Chan WL, Huang PH, Chen JW, Lin SJ. Usefulness of the CHADS2 score for prognostic stratification of patients with acute myocardial infarction. Am J Cardiol 2014;114:1309-14.

36. Kiliszek M, Szpakowicz A, Filipiak KJ, Kołtowski Ł, Południewska D, Szymański F, et al. CHA2DS2-VASc and R2CHA2DS2-VASc scores have predictive value in patients with acute coronary syndromes. Pol Arch Med Wewn 2015;125:545-52.

37. Rozenbaum Z, Elis A, Shuvy M, Vorobeichik D, Shlomo N, Shlezinger M, et al. CHA2DS2-VASc score and clinical outcomes of patients with acute coronary syndrome. Eur J Intern Med 2016;36:57-61.

38. Ünal S, Açar B, Yayla Ç, Balci MM, Ertem A, Kara M, et al. Importance and usage of the CHA2DS2-VASc score in predicting acute stent thrombosis. Coron Artery Dis 2016;27:478-82.

39. Aksoy F, Bagc1 A. Predictive value of ATRIA risk score for contrast-induced nephropathy after percutaneous coronary intervention for ST-segment elevation myocardial infarction. Rev Assoc Med Bras (1992) 2019;65:1384-90. 